\title{
Improved forecasts of atmospheric rivers through systematic reconnaissance, better modelling, and insights on conversion of rain to flooding
}

\author{
David A. Lavers (10 ${ }^{1 凶}$, F. Martin Ralph ${ }^{2}$, David S. Richardson (1) ${ }^{1} \&$ \\ Florian Pappenberger ${ }^{1}$
}

\begin{abstract}
Atmospheric rivers lie behind many extreme precipitation and flood episodes in the midlatitudes. Better forecasts of atmospheric rivers and their impacts could help with preparedness. Here we argue that a comprehensive and systematic observational campaign could help advance numerical weather prediction, and thereby provide a path towards much improved forecasts of atmospheric rivers. We envision an interdisciplinary European-American observational campaign in the North Atlantic to identify and address numerical weather prediction errors in atmospheric rivers, and the associated extratropical cyclones. Insights gained could be applied in other regions. With improved understanding of the physiography of river basins and insights into their flood response to extreme precipitation, the impacts of atmospheric rivers can also be forecast more reliably.
\end{abstract}

n early 2020, northern Europe experienced widespread flooding. The period had heightened cyclonic activity across the North Atlantic and was punctuated by two storms, Ciara and Dennis, on 9 and 16 February, respectively. Within these storms, it was the Atmospheric River (AR) component that was mostly behind the large precipitation totals and flooding. ARs are a global phenomenon linked to the extratropical storm tracks, and in early February 2020 just before the European storms, a different AR brought major flooding (and beneficial snowpack) to the western United States. The socioeconomic effects are representative of the roles ARs play in hydroclimate, flooding, and water supply. The needs for better forecasts and the range of disciplines involved (meteorology, hydrology, and water resources management) provide the motivation for this perspective on the forecasting of ARs and their impacts.

This article describes ARs and their impacts, and presents recent advances in forecasting including modelling improvements, newly available AR forecast products, and the AR Reconnaissance observational campaign across the northeast Pacific. We follow this with a vision to improve forecasts of ARs and their impacts by (1) lengthening their skilful forecast horizon through better modelling and better observations to initialise the forecasts, (2) considering river basin properties, and (3) proposing an AR Reconnaissance campaign in the North Atlantic. The interdisciplinary approach required is also discussed.

\footnotetext{
${ }^{1}$ European Centre for Medium-Range Weather Forecasts (ECMWF), Shinfield Park, Reading RG2 9AX, UK. ${ }^{2}$ Center for Western Weather and Water Extremes (CW3E), Scripps Institution of Oceanography, University of California, San Diego, La Jolla, California, USA. ${ }^{\circledR}$ email: david.lavers@ecmwf.int
} 


\section{Atmospheric Rivers}

The horizontal flux of water vapour across the mid-latitudes largely occurs within ARs ${ }^{1,2}$. Typically around $2000 \mathrm{~km}$ in length and $800 \mathrm{~km}$ in width ${ }^{3}$, these long and narrow regions are located ahead of the cold front within an extratropical cyclone ${ }^{4}$ and are frequently connected to a low-altitude jet stream ${ }^{5}$. Their moisture can originate from both local mid-latitude sources over which the extratropical cyclones travel and from more remote, sometimes tropical, regions ${ }^{6}$, and strikingly ARs often contain larger freshwater fluxes than the Amazon River ${ }^{1,7}$. There can also be an ascending airstream known as a warm conveyor belt (WCB $)^{8-11}$ that feeds off the moisture in an AR. This WCB flow usually slopes along the warm front toward the upper troposphere forming the comma-shaped cloud feature of an extratropical cyclone. It is in this region that precipitation is produced and where the latent heat release due to the condensation of water vapour can affect the atmospheric circulation ${ }^{12-14}$.

Interest in ARs has grown rapidly in recent years, as their key role in the global water cycle has become clearer. In particular, they have been found responsible for multiple hazards, most notably extreme precipitation and flooding in coastal mid-latitude zones in Europe ${ }^{15-17}$, western North America ${ }^{18,19}$, South America $^{20}$, and New Zealand ${ }^{21}$. Two AR events in February 2020 are presented herein to exemplify their features and hydrological impacts, one in the Pacific Northwest (Fig. 1a) and another, Storm Dennis, across northwest Europe (Fig. 1b). Each storm had typical Eulerian AR characteristics of large vertically integrated horizontal water vapour transport (integrated vapour transport, IVT) and a parent extratropical cyclone located away from the AR, which in the case of Dennis had extreme IVT exceeding 1200 $\mathrm{kg} \mathrm{m}^{-1} \mathrm{~s}^{-1}$ and a minimum surface pressure approaching 920 $\mathrm{hPa}$, respectively. The important part played by the large-scale atmospheric circulation 22 in steering these two ARs (and hence in determining the location of downstream precipitation) is illustrated by the mean sea-level pressure field in Fig.1. In terms of impacts, the Cascades in Washington in the Pacific Northwest received over $250 \mathrm{~mm}$ of precipitation in the 7-day period around the $\mathrm{AR}$, and western regions of Britain had over $150 \mathrm{~mm}$ recorded in $<3$ days $^{23}$; major flooding also followed. The insured damages across Europe associated with Dennis have been estimated at 286 million euros; these losses chiefly being in the UK, Germany, and
Belgium $^{24}$. In the western United States, more broadly, ARs are the major driver of flood damages, where over $90 \%$ of all flood damages are due to AR storms in major coastal areas, highlighting their important socioeconomic effects ${ }^{25}$. Furthermore, ARs can occur concurrently with wind extremes ${ }^{26}$ and high sea levels ${ }^{27}$.

There are, however, benefits from the precipitation delivered by ARs to mid-latitude land masses. For example, in California they can provide up to $50 \%$ of the annual precipitation ${ }^{28}$ and supply beneficial snowpack (as with the AR in Fig. 1a), which makes them crucial for water resources. Moreover, precipitation in California tends to occur in a few large winter storms and therefore the occurrence or non-occurrence of these few AR events can determine the amount of water available in the water year. Thus, the management of the water received during these storms is of great importance to public water supply and the way in which ARs cut across the meteorological, hydrological, and user communities illustrates how interdisciplinary efforts are needed when dealing with their effects.

Given the significant part ARs play in extreme precipitation, flooding, and water supply in mid-latitude regions, it is critical to be able to accurately forecast ARs and the large-scale atmospheric circulation using numerical weather prediction (NWP) systems to provide warnings and awareness of these events (at all relevant time scales, from days to seasons); and studies show that global NWP models do have useful skill in forecasting AR occurrence ${ }^{29-34}$. A recent evaluation using the ensemble forecasts-multiple forecasts run to obtain a probability distribution of the future weather ${ }^{35}$ from the European Centre for Medium-Range Weather Forecasts (ECMWF) Integrated Forecasting System found that the AR structure, as defined by IVT, was also forecast skilfully ${ }^{36}$. As the forecast lead time increased, however, the uncertainty of forecasted IVT grew substantially which resulted in precipitation uncertainties over land. This uncertainty in the IVT, and hence the issues in determining the intensity and timing of AR conditions, as well as the locations to be affected (even at short lead times), can create substantial problems for the responders who are responsible for flood preparedness and water resources management. It is with these thoughts in mind that we are motivated to present this perspective on improving the forecasts of ARs and in turn their impacts.

\section{a. 00UTC 05 Feb. 2020}

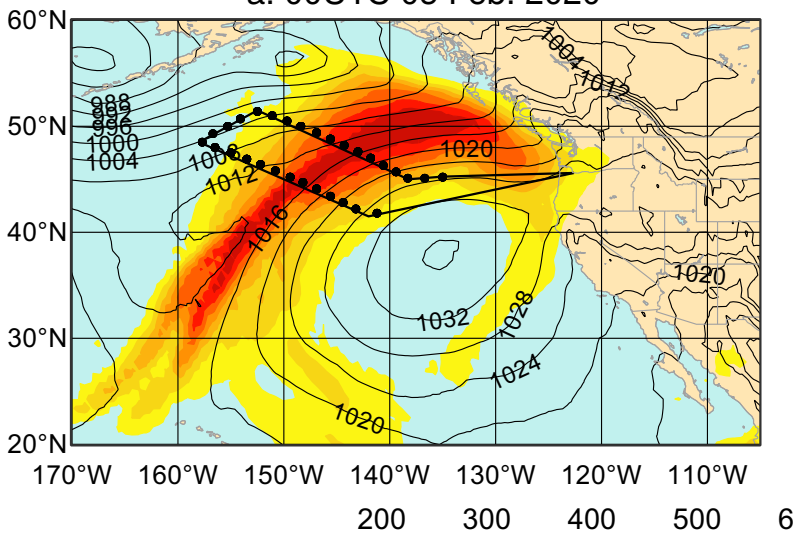

b. 00UTC 16 Feb. 2020

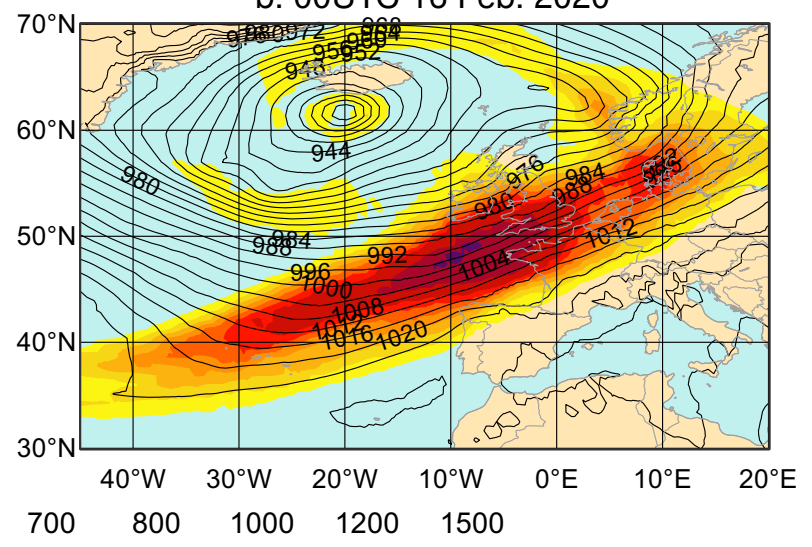

IVT $\left(\mathrm{kg} \mathrm{m}^{-1} \mathrm{~s}^{-1}\right)$

Fig. 1 Two Atmospheric River events in February 2020. The vertically integrated horizontal water vapour transport (IVT; shaded contours) and mean sealevel pressure (black line contours) in the analysis of the European Centre for Medium-Range Weather Forecasts (ECMWF) control forecast at (a) 00UTC 5 February 2020 across the northeast Pacific Ocean and (b) 00UTC 16 February 2020 across the North Atlantic Ocean. The Atmospheric River (AR) in a was sampled as part of AR Recon and the black dots overlaying the thick black lines correspond to the dropsonde locations and the aircraft flight track out of Portland, Oregon, respectively. 


\section{Recent advances in forecasting}

The AR properties of interest to forecast users are different at various lead times. First, at seasonal time scales, it is sufficient to know the AR frequency and the associated total precipitation within a season across a region (e.g., northeast Pacific). This may be obtained by the counting of AR events and accumulating the forecast precipitation following the application of an AR detection algorithm ${ }^{37}$ to seasonal forecasts. Second, in the late medium-range and early extended-range forecast horizons (forecast week-2 and week-3), the approximate time period when an area (e.g., river basin) may experience extreme precipitation and flooding is desired; this awareness provides the opportunity for discussions to take place about appropriate event preparations. Finally, the most challenging questions for forecast usersthe main foci of this perspective piece-are in the short and early medium-range (1-7 days), a time when it is essential to know the intensity, location, and timing of ARs (the improvement of the forecasts at these lead times will also affect the forecast skill at longer ranges). The uncertainties that can arise, for example from poor observation coverage within the storms over ocean areas or from low predictability atmospheric features, such as mesoscale frontal waves ${ }^{38}$, present users with difficult decisions on which river basins may flood, and how to manage precious water resources. Recent forecasting advances that have made progress towards improving AR forecasts are now detailed in this section.

Global NWP centres regularly upgrade their forecast systems to include new earth-system process understanding, the latest observation sources (e.g., new satellite retrievals), and more efficient and powerful supercomputers. These updates have all led to a continuous improvement in $\mathrm{NWP}^{39}$ and more skilful forecasts of extreme events, such as ARs. An important step to exploit these better forecasts is the development of products to visualise and extract the relevant forecast information. Two newly available AR forecast products are the Extreme Forecast Index (EFI) for water vapour flux ${ }^{31,32,40,41}$ and the AR Scale ${ }^{42}$. The EFI compares the probability distribution of the ECMWF
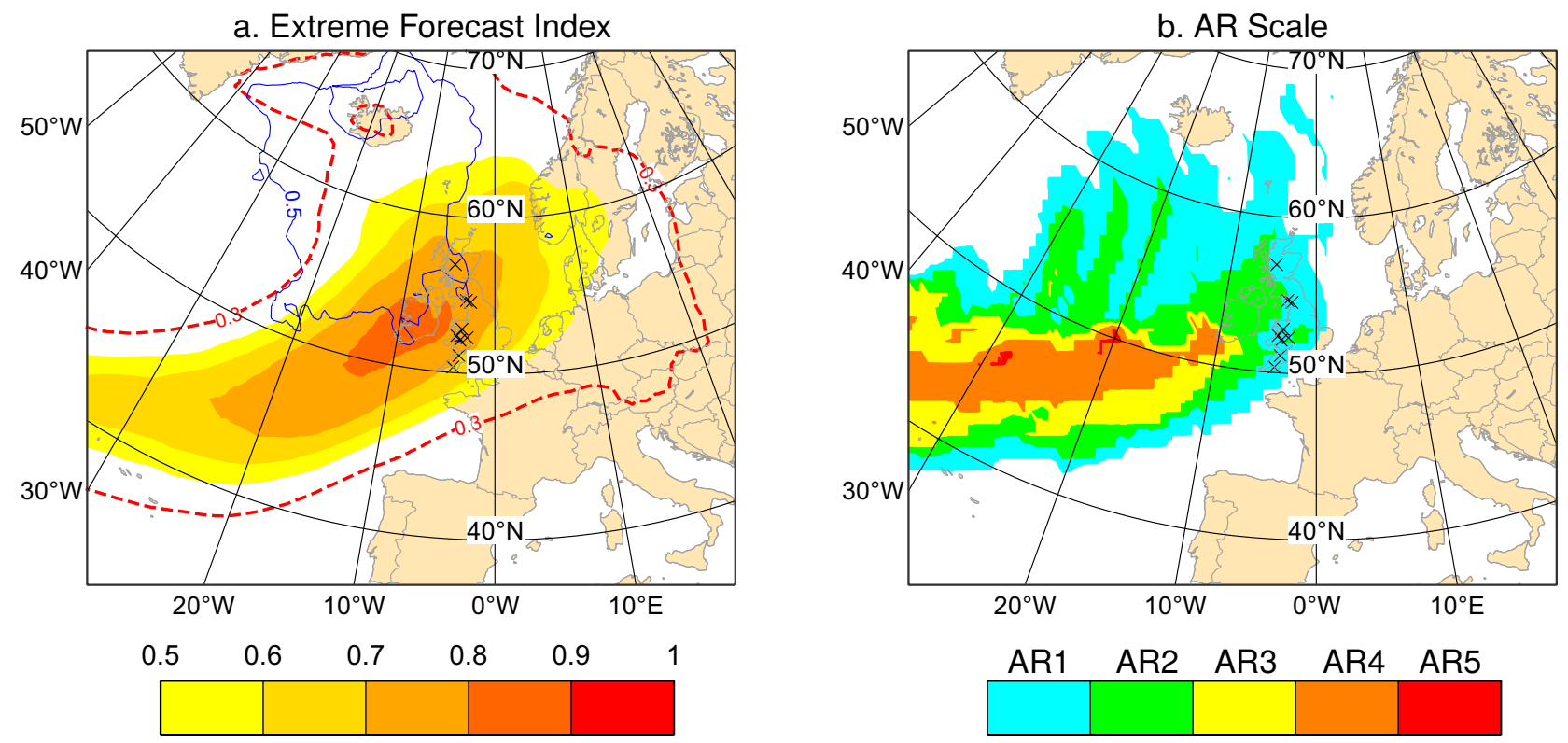

Fig. 2 Forecasting the Atmospheric River in storm Dennis. a Extreme Forecast Index (EFI) in the European Centre for Medium-Range Weather Forecasts (ECMWF) ensemble forecast for integrated vapour transport IVT (shaded contours and red dashed line) and total precipitation (blue contour; areas inside the contour denote EFI for precipitation > 0.5). b Atmospheric River (AR) Scale in the ECMWF control forecast. The forecasts were initialised at 00UTC 8 February 2020 and are valid for the period OOUTC 14 February 2020 to 00UTC 17 February 2020 (forecast days 7-9). The nine black crosses in each panel in western Britain indicate rain gauges in the synoptic network where the corresponding 3-day total exceeded $50 \mathrm{~mm}$. ensemble forecasts with its model climate; and the values range from -1 to 1 , where -1 indicates extremely low and 1 indicates extremely high values with respect to the model climate. The AR Scale uses two parameters, the maximum IVT and AR duration (i.e., the duration of at least minimal AR conditions, IVT $\geq$ $250 \mathrm{~kg} \mathrm{~m}^{-1} \mathrm{~s}^{-1}$ ) at a given geographic location and defines AR rankings from 1 to 5 .

Figure 2 illustrates the EFI and AR scale for Storm Dennis for the period 00UTC 14 February 2020 to 00UTC 17 February 2020 (during forecast days 7-9). First, a clear sign of the AR within Dennis is found in both products which elucidates the high water vapour flux and hence the atmospheric processes at play, thus improving understanding of the forecast event. This also suggests that although the two product formulations draw out and communicate different information, they are complementary in identifying the AR conditions. Second, in Fig. 2a visual inspection of the areas with EFI exceeding 0.5 shows that at these forecast lead times the EFI for IVT (yellow filled contour) is more skilful than the precipitation EFI (blue line contour) in discriminating the large observed precipitation totals in western Britain (black crosses). This highlights that the EFI for IVT can afford earlier awareness of the locations likely to be affected, which corroborates previous research ${ }^{31}$. Therefore, this AR product has made progress in realising improved precipitation forecasts during ARs.

A crucial advancement of late has been the development of an observational campaign called AR Reconnaissance (AR Recon) in the northeast Pacific ${ }^{43}$. The aim of AR Recon is to improve the science and forecasts of landfalling ARs to help better inform decision-makers on water management and flooding in the western United States through improving NWP models. Unique observations are collected from dropsondes from up to three aircraft flying simultaneously, extra radiosonde launches, drifting ocean buoys, and airborne radio occultation (the positions of the dropsondes launched from one aircraft in an AR Recon intensive observing period on 5 February 2020 are shown in Fig. 1a). The locations to sample are largely determined using both adjoint and ensemble methods to estimate the forecast sensitivity of west 
coast United States precipitation to moisture and wind conditions over the eastern Pacific before AR landfall ${ }^{43}$. These regions can include the strong IVT filament in the AR and upper-level circulations seen as potential vorticity anomalies. With the gathered observations, it is then possible to (1) improve the next NWP forecast by assimilating these observations from the data-sparse northeast Pacific and (2) undertake diagnostic studies $36,44,45$ and model experiments to identify model biases and improve the data assimilation and modelling systems, respectively. AR Recon has been developed as a Research and Operations Partnership and is led by the Center for Western Weather and Water Extremes (at Scripps Institution of Oceanography) and the US National Weather Service/National Centers for Environmental Prediction, together with its core partners of the US Naval Research Laboratory, US Air Force, the National Center for Atmospheric Research, ECMWF, and multiple academic institutions. As of winter 2019/20, it has also been formally incorporated in the US National Winter Season Operations Plan ${ }^{46}$. We furthermore note a complementary campaign over the North Atlantic Ocean in 2016, the North Atlantic Waveguide and Downstream Impact Experiment (NAWDEX) ${ }^{47}$, which has aided our understanding (and so fed into improved modelling) of the large-scale flow, extratropical cyclones, and the WCB.

\section{A path to improved forecasts and the interdisciplinary approach required}

Following the advances in AR forecasting obtained by NWP improvements, AR forecast products, and observational campaigns, such as AR Recon, we now set out a vision on how to progress this further. A primary challenge is how to reduce the uncertainty of the intensity, location, and timing of ARs in the short and early medium-range (1-7 days), which will also influence the forecast skill of the WCB outflow and therefore the jet stream and large-scale atmospheric circulation (e.g., highpressure ridges) ${ }^{13,48}$. To this end, the first important requirement is the continued improvement in NWP, which will, in turn, lead to a lengthening of the skilful forecast horizon. This could be achieved via the better representation of physical processes (through, e.g., higher model resolution), the coupling of more physical processes via an efficient earth-system data assimilation approach, and by improved modelling of the connections between the low-level water vapour in ARs and WCBs, and the mid- and upper-level atmospheric flow. Another issue to address is the development of a stable boundary layer beneath the AR, as it advects warm air over cooler water. This condition can cause the ocean surface to become relatively decoupled from the strong winds in the $\mathrm{AR}$ aloft and represents a challenge for data assimilation systems to properly distribute ocean surface condition information vertically into the model. Furthermore, the procurement of temperature, water vapour content, and wind observations with the fidelity to capture the sharp gradients across extratropical cyclones, ARs, and the jet stream is vital. For example, the reduction of errors in the tropopause structure ${ }^{49}$ may lead to better forecasting of the cyclone and AR development, and in turn at later forecast times, the large-scale circulation and weather regimes. The routine deployment of dropsondes (e.g., in AR Recon) and the launch of the AEOLUS wind lidar ${ }^{50}$ mark progress in this area, but new observation platforms are needed over the generally data-sparse oceans where ARs form. Also, research into the way data assimilation systems use observations is needed to ensure that all of the available information is used. Finally, for AR applications at extended-range and seasonal forecast horizons, knowledge of the role of the largescale circulation in modulating AR occurrence and the further investigation and identification of sources of extended-range predictability and tropical-extratropical connections (e.g., the Madden-Julian Oscillation ${ }^{51}$ ) could be beneficial.

The hydrological impact of an AR event is to a large extent determined by the AR interaction with the land surface, and many aspects of the land surface physiography can play an important part in translating the water vapour within an AR into precipitation and river discharge. These include the river basin antecedent conditions (i.e., soil moisture), which dictate how much precipitation the basin can absorb; terrain characteristics of height and orientation, and in turn, the potential orographic enhancement of precipitation in certain areas and rain shadows in others ${ }^{19}$; underlying bedrock and soil type, where low permeability regions (e.g., granite) preclude infiltration and permeable regions (e.g., chalk) allow water to infiltrate deep into groundwater reservoirs; and land use, such as the presence of urban areas and lakes/reservoirs. Although the river basin properties that affect the river discharge and floods are mostly well known, it is the large heterogeneities and hence unique characteristics across regions that lead to a varying attenuation of the precipitation-to-discharge signal in different places ${ }^{19,52,53}$. We suggest that the detailed investigation (possibly partly via increased instrumentation in basins) of the role of the land surface physiography in the translation of AR precipitation into river discharge in adjacent river basins would improve understanding of the flood response potentially resulting in better flood forecasting capabilities. This interdisciplinary activity, which may also include hydrological modelling, would be dependent on engaging meteorologists, hydrologists, and water managers, and this could be developed and tested following the example of the US Army Corps of Engineers' atmospheric-riverfocused Forecast-Informed Reservoir Operations Program ${ }^{54}$.

A key consideration we forward for improving forecasts of ARs and their impacts is the organisation of a combined European-American observational campaign in the North Atlantic, named herein 'AR Recon Atlantic'. This proposed campaign would build on the operating procedures and airborne weather reconnaissance strategies developed in AR Recon in the northeast Pacific and on the results from NAWDEX ${ }^{47}$ over the North Atlantic, to probe ARs, the associated WCB, and mesoscale dynamical features (e.g., mesoscale frontal waves). The esprit de corps that could be fostered through the interdisciplinary and intercontinental collaboration of meteorologists, hydrologists, and instrument operators could lead to new discoveries that advance the better representation of the global water cycle in NWP; the ultimate result being the improved forecast skill of ARs and their impacts. A hypothetical set-up of three research aircraft sampling different features in an intensive observing period is shown in Fig. 3. For example, the opportunities to fly transects and deploy dropsondes across the strong air temperature and wind speed (jet stream) gradients off the east of North America could provide insight into the way NWP systems handle this critical region for extratropical cyclone development. Further diagnostic studies on how the IVT in ARs and mesoscale storm features are resolved in NWP forecasts would also elucidate any model biases or uncertainties, which following future tailored NWP improvements towards these issues, could improve forecasts. Moreover, a global simultaneous AR campaign in the western and eastern Pacific Ocean and North Atlantic Ocean is a possibility, which may lead to even greater insights and forecast gains via detailed concurrent observations of the large-scale atmospheric circulation and Rossby Wave patterns across the northern hemisphere. It is also envisaged that in the future this campaign strategy could then be applied in the southern hemisphere. 


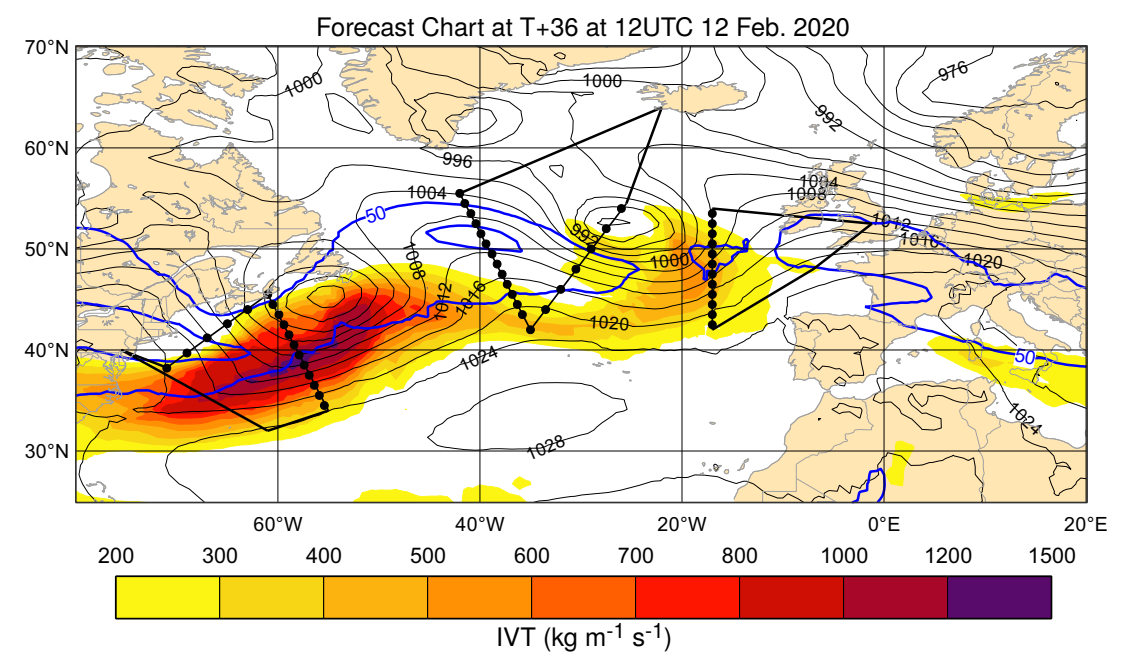

Fig. 3 A hypothetical intensive observing period in Atmospheric River Reconnaissance Atlantic. The integrated vapour transport (IVT; shaded contours), mean sea-level pressure (black line contours), and $250 \mathrm{hPa}$ winds (thick blue line contours at 50 and $75 \mathrm{~m} \mathrm{~s}^{-1}$ ) in the European Centre for Medium-Range Weather Forecasts control forecast at 36-h. lead time at 12 UTC 12 February 2020 (this is a few days before the arrival of storm Dennis in Europe). The thick black solid lines are the possible flight tracks of three aircraft from Europe and the United States and the black dots overlaying the thick black lines correspond to potential dropsonde locations. Depending on aircraft availability, Atmospheric River Reconnaissance Atlantic could, e.g., have a total of 15 flights over a 6-week campaign period.

\section{Conclusions}

ARs were predominantly responsible for the large precipitation totals causing flooding in northern Europe and the Pacific Northwest of North America in early 2020. Following the associated major flooding and socioeconomic damages, this perspective piece is motivated by the needs for better forecasts of ARs and their impacts and the close interdisciplinary collaboration required (meteorology, hydrology, water resources management). In this article, we first define ARs, introduce the vital roles they play in hydroclimate, flooding, and water supply, and discuss their current forecast skill. Second, we outline the recent advances in AR forecasting from NWP improvements, newly available AR forecast products, and the AR Recon programme across the northeast Pacific.

The main focus of this perspective is then the outlining of a vision to improve forecasts of ARs and their impacts. We believe this may be achieved through three principal ways: (1) the continued improvement in NWP systems and thus the lengthening of the skilful forecast horizon, e.g., by better resolving the interaction between the water vapour and latent heat release in ARs and WCBs, and the mid- and upper-level atmospheric flow, as well as examining the stable boundary conditions characteristic of AR conditions; (2) the detailed investigation of how heterogeneities in the land surface physiography in sometimes adjacent river basins affect how AR precipitation is converted into river discharge; and (3) the proposal of an interdisciplinary European-American observational campaign in the North Atlantic, named herein 'AR Recon Atlantic'. The vision of an intercontinental campaign would combine expertise and resources, thus providing ample opportunities to comprehensively sample extratropical cyclones, ARs, WCBs, and mesoscale atmospheric features to identify any forecast issues over the North Atlantic Ocean in our current NWP systems. Before improvements can be made in modelling the global water cycle, and in particular the AR transport mechanism and its impacts, we need to identify the current errors and uncertainties so that modelling efforts can be targeted correctly. It is then that a better representation of ARs, WCBs, and their impacts may be afforded leading to socioeconomic benefits. We call for the disciplines involved and required to come together to make such a vision a reality.

\section{Data availability}

The data used to create the figures are stored in the ECMWF archive (https://www. ecmwf.int/en/forecasts/datasets/archive-datasets).

Received: 29 May 2020; Accepted: 5 October 2020; Published online: 28 October 2020

\section{References}

1. Zhu, Y. \& Newell, R. E. A proposed algorithm for moisture fluxes from atmospheric rivers. Mon. Weather Rev. 126, 725-735 (1998).

2. Ralph, F. M., Dettinger, M. D., Cairns, M. M., Galarneau, T. J. \& Eylander, J. Defining "Atmospheric River": how the glossary of meteorology helped resolve a debate. Bull. Am. Meteor. Soc 99, 837-839 (2018). This article provides the definition of an atmospheric river.

3. Ralph, F. M. et al. (eds) In Atmospheric Rivers p. 286 (Springer, 2020).

4. Ralph, F. M., Neiman, P. J. \& Rotunno, R. Dropsonde observations in lowlevel jets over the Northeastern Pacific Ocean from CALJET-1998 and PACJET-2001: mean vertical-profile and atmospheric-river characteristics. Mon. Weather Rev. 133, 889-910 (2005).

5. Browning, K. A. \& Pardoe, C. W. Structure of low-level jet streams ahead of mid-latitude cold fronts. Quart. J. Roy. Meteor. Soc. 99, 619-638 (1973).

6. Sodemann, H. \& Stohl, A. Moisture origin and meridional transport in atmospheric rivers and their association with multiple cyclones. Monthly Weather Rev. 141, 2850-2868 (2013).

7. Ralph, F. M. et al. Dropsonde observations of total integrated water vapor transport within North Pacific atmospheric rivers. J. Hydrometeor. 18, 2577-2596 (2017).

8. Browning, K. A. Conceptual models of precipitation systems. Weather Forecasting 1, 23-41 (1986).

9. Wernli, H. \& Davies, H. C. A Lagrangian-based analysis of extratropical cyclones. I: the method and some applications. Quart. J. Roy. Meteor. Soc. 123, 467-489 (1997).

10. Madonna, E., Wernli, H., Joos, H. \& Martius, O. Warm conveyor belts in the ERA-Interim dataset (1979-2010). Part I: climatology and potential vorticity evolution. J. Climate 27, 3-26 (2014).

11. Sodemann, H. et al. (eds) In Atmospheric Rivers p. 286 (Springer, 2020).

12. Doyle, J. D., Amerault, C., Reynolds, C. A. \& Reinecke, P. A. Initial condition sensitivity and predictability of a severe extratropical cyclone using a moist adjoint. Monthly Weather Rev. 142, 320-342 (2014).

13. Schäfler, A. \& Harnisch, F. Impact of the inflow moisture on the evolution of a warm conveyor belt. Quart. J. Roy. Meteor. Soc. 141, 299-310 (2015). 
14. Rodwell, M. J., Richardson, D. S., Parsons, D. B. \& Wernli, H. Flow-dependent reliability: a path to more skillful ensemble forecasts. Bull. Am. Meteor. Soc. 99, 1015-1026 (2018).

15. Lavers, D. A. et al. Winter floods in Britain are connected to atmospheric rivers. Geophys. Res. Lett. 38, L23803 (2011).

16. Lavers, D. A. \& Villarini, G. The nexus between atmospheric rivers and extreme precipitation across Europe. Geophys. Res. Lett. 40, 3259-3264 (2013).

17. Ramos, A. M., Trigo, R. M., Liberato, M. L. \& Tomé, R. Daily precipitation extreme events in the Iberian Peninsula and its association with atmospheric rivers. J. Hydrometeor. 16, 579-597 (2015).

18. Ralph, F. M. et al. Flooding on California's Russian River: role of atmospheric rivers. Geophys. Res. Lett. 33, L13801 (2006)

19. Neiman, P. J., Schick, L. J., Ralph, F. M., Hughes, M. \& Wick, G. A. Flooding in western Washington: the connection to atmospheric rivers. J. Hydrometeor. 12, 1337-1358 (2011).

20. Viale, M. \& Nunez, M. N. Climatology of winter orographic precipitation over the subtropical central Andes and associated synoptic and regional characteristics. J. Hydrometeor. 12, 481-507 (2011).

21. Kingston, D. G., Lavers, D. A. \& Hannah, D. M. Floods in the Southern Alps of New Zealand: the importance of atmospheric rivers. Hydrol. Process. 30, 5063-5070 (2016).

22. Pasquier, J. T., Pfahl, S. \& Grams, C. M. Modulation of atmospheric river occurrence and associated precipitation extremes in the North Atlantic Region by European weather regimes. Geophys. Res. Lett. 46, 1014-1023 (2019).

23. UK Met Office. Record Breaking Rainfall. https://www.metoffice.gov.uk/ weather/warnings-and-advice/uk-storm-centre/storm-dennis (UK Met Office, 2020).

24. Insured losses from Europe's Storm Victoria (aka Dennis) estimated at $€ 286 \mathrm{M}$ : PERILS. Insurance J. https://www.insurancejournal.com/news/ international/2020/03/30/562719.htm (2020).

25. Corringham, T. W., Ralph, F. M., Gershunov, A., Cayan, D. R. \& Talbot, C. A. Atmospheric rivers drive flood damages in the western United States. Sci. Adv. 5, eaax4631 (2019).

26. Waliser, D. \& Guan, B. Extreme winds and precipitation during landfall of atmospheric rivers. Nat. Geosci. 10, 179-183 (2017).

27. Khouakhi, A. \& Villarini, G. On the relationship between atmospheric rivers and high sea water levels along the US West Coast. Geophys. Res. Lett. 43, 8815-8822 (2016).

28. Dettinger, M. D., Ralph, F. M., Das, T., Neiman, P. J. \& Cayan, D. Atmospheric rivers, floods, and the water resources of California. Water 3, 445-478 (2011).

29. Baggett, C. F., Barnes, E. A., Maloney, E. D. \& Mundhenk, B. D. Advancing atmospheric river forecasts into subseasonal-to-seasonal time scales. Geophys. Res. Lett. 44, 7528-7536 (2017).

30. DeFlorio, M. J. et al. Global assessment of atmospheric river prediction skill. J. Hydrometeor. 19, 409-426 (2018).

31. Lavers, D. A., Pappenberger, F., Richardson, D. S. \& Zsoter, E. ECMWF Extreme Forecast Index for water vapor transport: a forecast tool for atmospheric rivers and extreme precipitation. Geophys. Res. Lett. 43, 11,852-11,858 (2016).

32. Lavers, D. A., Zsoter, E., Richardson, D. S. \& Pappenberger, F. An assessment of the ECMWF extreme forecast index for water vapor transport during boreal winter. Weather Forecast. 32, 1667-1674 (2017). This paper describes the ECMWF Extreme Forecast Index product for integrated vapour transport and highlights the increased possible awareness of atmospheric rivers and extreme precipitation.

33. Nayak, M. A., Villarini, G. \& Lavers, D. A. On the skill of numerical weather prediction models to forecast atmospheric rivers over the central United States. Geophys. Res. Lett. 41, 4354-4362 (2014).

34. Wick, G. A., Neiman, P. J., Ralph, F. M. \& Hamill, T. M. Evaluation of forecasts of the water vapor signature of atmospheric rivers in operational numerical weather prediction models. Weather Forecast. 28, 1337-1352 (2013).

35. Leutbecher, M. \& Palmer, T. N. Ensemble forecasting. J. Comput. Phys. 227, 3515-3539 (2008).

36. Lavers, D. A. et al. The gauging and modeling of rivers in the sky. Geophys. Res. Lett. https://doi.org/10.1029/2018GL079019 (2018).

37. Rutz, J. J. et al. The atmospheric river tracking method intercomparison project (ARTMIP): quantifying uncertainties in atmospheric river climatology. J. Geophys. Res. 2019, 13777-13802 (2019).

38. Martin, A. C., Ralph, F. M., Wilson, A., DeHaan, L. \& Kawzenuk, B. Rapid cyclogenesis from a mesoscale frontal wave on an atmospheric river: impacts on forecast skill and predictability during atmospheric river landfall. $J$. Hydrometeor. 20, 1779-1794 (2019).

39. Bauer, P., Thorpe, A. \& Brunet, G. The quiet revolution of numerical weather prediction. Nature 525, 47-55 (2015).
40. Lavers, D. A. et al. Earlier awareness of extreme winter precipitation across the western Iberian Peninsula. Meteorol. Appl. 25, 622-628 (2018)

41. Lavers, D., Tsonevsky, I., Richardson, D. \& Pappenberger, F. The Extreme Forecast Index for water vapour flux, ECMWF Newslett. 160, https://www. ecmwf.int/en/newsletter/160/news/extreme-forecast-index-water-vapour-flux (2019).

42. Ralph, F. M. et al. A scale to characterize the strength and impacts of atmospheric rivers. Bull. Am. Meteor. Soc. 100, 269-289 (2019).

43. Ralph, F. M. et al. West Coast forecast challenges and development of atmospheric river reconnaissance. Bull. Am. Meteor. Soc., 101, E1357-E1377, https://doi.org/10.1175/BAMS-D-19-0183.1 (2020). This paper provides an overview of Atmospheric River Reconnaissance in the northeast Pacific which is key to the ideas proposed for AR Recon Atlantic.

44. Stone, R. E. et al. Atmospheric river reconnaissance observation impact in the navy global forecast system. Monthly Weather Rev. 148, 763-782 (2020).

45. Lavers, D. A. et al. Forecast errors and uncertainties in Atmospheric Rivers. Weather Forecast. https://doi.org/10.1175/WAF-D-20-0049.1 (2020).

46. National Winter Season Operations Plan. Winter Season Reconnaissance https://www.ofcm.gov/publications/nwsop/nwsop2.htm (2019).

47. Schäfler, A. et al. The North Atlantic Waveguide and Downstream Impact Experiment. Bull. Amer. Meteor. Soc. 99, 1607-1637 (2018). This paper describes the NAWDEX observational campaign in the North Atlantic and AR Recon Atlantic would build on these findings.

48. Grams, C. M., Magnusson, L. \& Madonna, E. An atmospheric dynamics perspective on the amplification and propagation of forecast error in numerical weather prediction models: a case study. Quart. J. R. Meteor. Soc. 144, 2577-2591 (2018).

49. Schäfler, A. et al. Observation of jet stream winds during NAWDEX and characterization of systematic meteorological analysis errors. Monthly Weather Rev. https://doi.org/10.1175/MWR-D-19-0229.1 (2020).

50. Rennie, M. \& Isaksen, L. Use of Aeolus observations at ECMWF. ECMWF Newslett. 163, https://www.ecmwf.int/en/newsletter/163/news/use-aeolusobservations-ecmwf (2020).

51. Guan, B., Waliser, D. E., Molotch, N. P., Fetzer, E. J. \& Neiman, P. J. Does the Madden-Julian oscillation influence wintertime atmospheric rivers and snowpack in the Sierra Nevada? Monthly Weather Rev. 140, 325-342 (2012).

52. Ralph, F. M. et al. The impact of a prominent rain shadow on flooding in California's Santa Cruz mountains: a CALJET case study and sensitivity to the ENSO cycle. J. Hydrometeor. 4, 1243-1264 (2003).

53. Lavers, D. A., Villarini, G., Allan, R. P., Wood, E. F. \& Wade, A. J. The detection of atmospheric rivers in atmospheric reanalyses and their links to British winter floods and the large-scale climatic circulation. J. Geophys. Res. 117, D20106 (2012).

54. Jasperse J. et al. Preliminary viability assessment of Lake Mendocino forecast informed reservoir operations. Technical report. http://pubs.er.usgs.gov/ publication/70192184 (USGS, 2017).

\section{Acknowledgements}

D.A.L. is grateful to funding from the European Union Copernicus Emergency Management Service (Framework Contract number 198702). We also thank Brian Kawzenuk for calculating the AR scale in Fig. $2 b$.

\section{Author contributions}

D.A.L. developed and led the writing of the perspective. D.A.L. produced the figures. D. A.L., F.M.R., D.S.R., and F.P. discussed and edited the article.

\section{Competing interests}

The authors declare no conflicts of interest.

\section{Additional information}

Supplementary information is available for this paper at https://doi.org/10.1038/s43247 020-00042-1.

Correspondence and requests for materials should be addressed to D.A.L.

Peer review information Primary handling editor: Heike Langenberg.

Reprints and permission information is available at http://www.nature.com/reprints

Publisher's note Springer Nature remains neutral with regard to jurisdictional claims in published maps and institutional affiliations. 
(c) (i) Open Access This article is licensed under a Creative Commons Attribution 4.0 International License, which permits use, sharing, adaptation, distribution and reproduction in any medium or format, as long as you give appropriate credit to the original author(s) and the source, provide a link to the Creative Commons license, and indicate if changes were made. The images or other third party material in this article are included in the article's Creative Commons license, unless indicated otherwise in a credit line to the material. If material is not included in the article's Creative Commons license and your intended use is not permitted by statutory regulation or exceeds the permitted use, you will need to obtain permission directly from the copyright holder. To view a copy of this license, visit http://creativecommons.org/ licenses/by/4.0/.

(C) The Author(s) 2020 